\title{
Turismo de base comunitária com foco em gênero:
}

\author{
estudo de caso na Comunidade Morro Santo Antônio, \\ Município de Itabira-MG
}

Community-based tourism with emphasis in gender: case study at Morro Santo Antônio Community, Municipality of Itabira-MG

El turismo comunitario con enfoque de género: un estudio de caso en la Comunidad Morro Santo Antônio, Itabira-MG

http://dx.doi.org/10.18472/cvt.16n2.2016.1091

Marina Araújo 〈amarinaaraujo@yahoo.com.br >

Instituto Brasileiro do Meio Ambiente e dos Recursos Naturais Renováveis, Ibama, Brasil.

CRONOLOGIA DO PROCESSO EDITORIAL

Recebimento do artigo: 04-set-2015

Aceite: 17 -jun-2016

FORMATO PARA CITAÇÃO DESTE ARTIGO

ARAÚJO, M. Turismo de base comunitária com foco em gênero: estudo de caso na Comunidade Morro Santo Antônio, Município de Itabira-MG. Caderno Virtual de Turismo. Rio de Janeiro, v. 16, n. 2, p. 34-61, ago. 2016.

$$
\text { REALIZAÇÃO }
$$

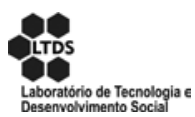

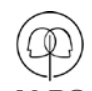

APOIO INSTITUCIONAL

COPPE
EDIÇÃO

PATROCÍNIO

IR⿴囗十日R 


\section{RESUMO}

As metodologias participativas com foco em gênero são aquelas que buscam promover sensibilização e capacitação para as relações de gênero. Seu uso pode contribuir para a elaboração de projetos turísticos locais, uma vez que por meio delas é possível identificar desigualdades de gênero, promover a real participação de mulheres e homens e, assim, combater a reprodução de condições desiguais no acesso aos benefícios do desenvolvimento da atividade turística em um determinado território. Nesse sentido, o objetivo deste artigo é apresentar os resultados do processo participativo na criação de uma proposta de autogestão do turismo de base comunitária com foco em gênero realizado na Comunidade Quilombola Morro Santo Antônio, localizada no município de Itabira, estado de Minas Gerais, Brasil. Observou-se, a partir deste estudo de caso, que o uso das metodologias participativas com foco em gênero aliado à proposta do turismo de base comunitária contribuiu de forma positiva para que a proposta de autogestão elaborada pela comunidade, além de ser mais crítica e contextualizada à sua realidade local, não reafirmasse as desigualdades de gênero existentes na mesma.

Palavras-chave: Turismo de Base Comunitária. Metodologias participativas. Gênero.

\section{ABSTRACT}

The participative methodologies with emphasis in gender are those who try to promote awareness and qualification for the gender relations. Their use can help to plan local tourist projects because through them it's possible to identify gender inequalities, to promote real participation of women and men and, therefore, to combat the reproduction of unequal conditions in the access to the benefits of development tourist activity. In this sense, the aim of this article is to present the results of the participatory process in creating a proposal for self-management of community-based tourism with emphasis in gender built in Morro Santo Antônio Quilombola Community located in Itabira, Minas Gerais, Brazil. It was observed from this case study, that the use of participative methodologies with emphasis on gender ally to the community-based tourism proposal contributed positively to the self-management proposal made by the community, besides being more critical and contextualized to their local reality, did not reaffirm gender inequalities already established in it.

Keywords: Community-based tourism. Participative methodologies. Gender.

\section{RESUMEN}

Las metodologías participativas con enfoque de género son las que tratan de promover la sensibilización y creación de capacidad para las relaciones de género. Su uso puede contribuir al desarrollo de proyectos de turismo locales, ya que a través de ellos es posible identificar las desigualdades de género, la promoción de la participación real de las mujeres y los hombres, y así luchar contra la desigualdad de condiciones en el acceso a los beneficios del desarrollo la actividad turística en un territorio determinado. En este sentido, el objetivo de este trabajo es presentar los resultados del proceso de participación en la creación de una propuesta de autogestión de turismo basado en la comunidad con un enfoque de género realizado en la Comunidad Quilombola Morro Santo Antônio situada en Itabira, Minas Gerais, Brasil. Se observó, a partir de este estudio de caso, que la utilización de metodologías participativas con enfoque en género aliada a la propuesta del turismo comunitario para que la propuesta de autogestión preparada por la comunidad, además de ser más crítica y contextualizada a su realidad local, no reafirmase las desigualdades de género existentes en la misma.

Palavras clave: Turismo comunitário. Metodologías participativas. Género. 


\section{INTRODUÇÃO}

É crescente, no campo do turismo, o número de publicações que confirmam a importância do turismo de base comunitária para o aumento da autonomia da população nos processos de decisão relativos ao desenvolvimento turístico em seu território (ARAÚJO, 2011; BESSA, 2011; FERNANDES, 2006; MENDONÇA, 2004; MITRAUD, 2003). Essa proposta de desenvolvimento participativo contrapõe-se ao modelo turístico convencional (implantado de "cima para baixo") e tem se configurado como um modelo de desenvolvimento mais justo e equitativo, uma vez que é construído com, para e pela comunidade e, dessa forma, condiz com as reais necessidades e anseios da população local em relação à atividade turística.

No entanto, na busca da equidade, entendida como a promoção da igualdade de oportunidades, é necessário conceber que as pessoas possuem diferentes necessidades, percepções e realidades, ainda que habitem um mesmo lugar. Concorda-se com Portella (2005), quando afirma que projetos que não consideram a existência e a condição diferenciada de homens e mulheres - sobre as quais irão incidir os impactos também diferenciados das ações desses projetos - terminam por consolidar desigualdades e injustiças seculares.

Nesse sentido, a adoção de metodologias participativas com foco em gênero no campo do turismo significaria uma mudança na perspectiva de trabalho: em vez de se intervir em um grupo, entendendo-o como uma unidade homogênea, passar-se-ia a reconhecer que homens e mulheres possuem diferentes necessidades e responsabilidades no desenvolvimento da atividade turística. Além disso, acredita-se que os projetos seriam mais eficazes e gerariam mais benefícios às comunidades se envolvessem ativamente as mulheres, valorizando seu papel, sua experiência e a importância do seu trabalho dentro da sociedade local (DI CIOMMO, 2007).

Diante do exposto, perguntou-se: como as metodologias participativas com foco em gênero poderiam contribuir para o início do planejamento turístico de base comunitária? Que tipo de resultado poderia ser alcançado a partir de sua aplicação no contexto desse planejamento turístico?

Sendo assim, o objetivo geral deste estudo de caso foi iniciar o desenvolvimento de uma proposta de turismo de base comunitária com foco em gênero na Comunidade Quilombola Morro Santo Antônio, município de Itabira, Minas Gerais, Brasil, como forma de se favorecer o empoderamento ${ }^{1}$ das mulheres em relação ao desenvolvimento da atividade turística em seu território, buscando reduzir as desigualdades de gênero.

Por meio da intervenção proposta na comunidade buscou-se contribuir para a construção de um pensamento crítico acerca do desenvolvimento do turismo em seu território; para a construção de uma proposta inicial de autogestão do turismo pela população; e para a maior inserção das mulheres nas decisões e, consequentemente, na dinâmica da atividade turística planejada para a localidade.

\footnotetext{
1 Tradução do termo "empowerment”, usado pelos americanos, cujo significado se aproxima dos termos "conscientização" e "reforço do poder" utilizados nas concepções de educação popular da década de 1980 (VERDEJO, 2006). 0 reforço do poder das mulheres se dá por meio do reconhecimento do seu papel dentro de sistemas econômicos, sociais, políticos, culturais e ambientais próprios e da sua participação ativa nesses sistemas.
} 


\section{A Comunidade Quilombola Morro Santo Antônio, Itabira, Minas Gerais, Brasil}

A Comunidade Quilombola Morro Santo Antônio localiza-se na zona rural do município de Itabira, na região central do estado de Minas Gerais, no Brasil. Sua história vincula-se ao passado escravocrata, entretanto, não há estudos históricos consolidados a respeito de sua origem específica. Dessa forma, a ocupação histórico-espacial da localidade é contada por meio das lembranças dos antigos moradores, em especial, da Tia Josefina, considerada a matriarca do Morro Santo Antônio.

Filha de escravos, Dona Josefina Lucas Evangelista nasceu livre em 1881 e lembrava-se que foi levada com seus irmãos, ainda crianças, para morar no Morro, o que leva a crer que a comunidade tenha sido fundada há, pelo menos, 135 anos. Segundo relatos, a localidade foi formada por escravos fugidos ou alforriados e por negros que trabalhavam na Fazenda do Girau, localizada onde hoje se encontra o Bairro da Pedreira, em Itabira, a aproximadamente $7 \mathrm{~km}$ da comunidade.

Dona Josefina morreu em 2002, aos 121 anos e, apesar de ter tido apenas um filho que faleceu com poucos meses de vida, deixou uma grande família que hoje é a Comunidade Morro Santo Antônio. É possível afirmar que a maioria dos moradores locais têm laços parentais com a matriarca. Acredita-se que por esse motivo a comunidade possui grande articulação em torno de interesses comuns.

Sua associação comunitária, denominada Associação Quilombola Morro Santo Antônio, foi constituída no ano de 1986 e permanece ativa até a atualidade. Por meio do estudo das atas de suas reuniões foi possível observar que do ano de 1986 a 1989 os encontros entre moradores foram realizados somente quando havia alguma demanda ou assunto urgente de interesse de todos a ser discutido.

A partir de 1990, as reuniões passaram a ser mensais e contar com a presença de 25 moradores, em média. Nesses encontros tratava-se de temas como reforma da igreja da localidade; realização de novenas, festas e quermesses; reivindicação de linha de ônibus coletivo e telefone público que atendesse à comunidade; necessidade de melhoria das estradas locais; realização de mutirões para limpeza do cemitério, da igreja e da sede da associação, entre outros.

Outro aspecto a ser destacado em relação à associação enquanto elemento de articulação da comunidade é a "Caixinha um ajudando o outro" criada em 1989. Essa fonte de arrecadação de recursos foi e ainda é utilizada para o auxílio das famílias com dificuldades financeiras. Segundo as atas das reuniões da associação, somente aqueles que contribuíssem para a sua manutenção - ainda que com pouco dinheiro - poderiam ser ajudados financeiramente.

Foi também a partir da mobilização dos atores locais nas reuniões da associação que a comunidade obteve reconhecimento pela Fundação Palmares como remanescente de quilombo em fevereiro de 2011. De acordo com a Portaria n. 98/2007 (BRASIL, 2007) os remanescentes das comunidades dos quilombos são os grupos étnico raciais, que assim se intitulam, com "trajetória histórica própria, dotados de relações territoriais específicas, com presunção de ancestralidade negra relacionada com formas de resistência à opressão histórica sofrida”. Dessa forma, por meio da iniciativa de alguns moradores do Morro Santo Antônio, realizou-se uma reunião na qual todos se reconheceram como descendentes de escravos, o que motivou a certificação da Fundação Palmares citada anteriormente.

No entanto, para a comunidade local, esse reconhecimento não só contribuiu de forma positiva para o fortalecimento da identidade cultural e histórica da localidade, como criou a possibilidade de implantação de uma nova atividade econômica em seu território: o turismo. Para os moradores locais, 
o desenvolvimento turístico poderia se configurar como uma alternativa de renda para a comunidade, cuja maioria é constituída por aposentados e, além disso, promover o retorno de várias pessoas que se mudaram do Morro para Belo Horizonte-MG e Itabira-MG em busca de emprego e melhores condições de vida.

Como visto, há três aspectos principais que poderiam colaborar para o desenvolvimento de uma proposta de turismo de base comunitária na Comunidade Quilombola Morro Santo Antônio: o desejo de se incorporar a atividade turística como uma fonte de renda pela comunidade; sua identidade reforçada através da certificação da Fundação Palmares; e sua mobilização em torno de interesses comuns por meio de sua associação comunitária.

Nesse sentido, acredita-se que a identidade e a mobilização dessas pessoas concorrem positivamente para que haja na comunidade consciência de sua trajetória histórica e de sua potencialidade, para que saiba realizar escolhas com autonomia e que desenvolva ações para concretizá-las. E, assim, como essas dimensões estão bem definidas nesse território, é possível fomentar o aprofundamento dos aspectos da participação e da parceria para a construção de um plano turístico comunitário.

Diante do exposto e analisando a realidade da Comunidade Morro Santo Antônio, afirma-se que ela possui cenário sociocultural que torna viáveis a execução de processos participativos em relação ao turismo e, especialmente, a efetivação de uma proposta de turismo de base comunitária com foco em gênero, o que justifica a sua escolha como foco deste estudo de caso.

\section{Metodologias participativas com foco em gênero e suas contribuições ao turismo de base comunitária}

Apesar de ainda serem pouco incorporadas aos projetos de desenvolvimento atuais, as metodologias participativas com foco em gênero existem desde o final da década de 1980 (PARISIUS, 1995). Segundo Parisius (1995) a maioria dessas metodologias surgiu dentro de agências de cooperação internacional, mudando o enfoque na promoção da mulher/mulher no desenvolvimento para as relações de gênero/ gênero e desenvolvimento, considerando a categoria gênero um instrumento essencial na análise, no planejamento, no monitoramento e na avaliação de qualquer projeto.

Concorda-se com Silva (2009) quando afirma que a pesquisa com foco em gênero deve envolver a análise das relações entre homens e mulheres e, principalmente, a interpretação de como acontecem e como são valorizadas socialmente as interações entre os gêneros em uma determinada sociedade. Esta é a proposta central do Gênero em Desenvolvimento (GED)² proposto por Zaldaña (1999, p. 10):

\footnotetext{
No enfoque GED, a análise das relações de poder se faz com o propósito de estabelecer quais são as estratégias que devem ser utilizadas para obter acesso e controle dos recursos políticos, econômicos e produtivos, assim como o emprego do tempo e o acesso aos benefícios pelas famílias e comunidades (...). A aplicação da perspectiva de Gênero em Desenvolvimento requer o compromisso das pessoas e do coletivo do projeto para criar oportunidades para que as mulheres se empoderem, a partir da valorização das formas em que se dão as relações de poder (se estas são equitativas ou desiguais), para, assim, poder transformá-las ${ }^{3}$.
}

\footnotetext{
2 Género en Desarrollo (tradução da autora).

3 Desde el enfoque GED, el análisis de las relaciones de poder se hace con el propósito de establecer cuáles son las estrategias que deben ser utilizadas para obtener el acceso y el control de los recursos políticos, económicos y productivos, así como el empleo del tiempo y el acceso a los beneficios de las familias y las comunidades (...). La aplicación de la perspectiva GED requiere del compromiso de las personas y del colectivo del proyecto a crear oportunidades para que las mujeres se empoderen, a partir de la valoración de las formas en que se dan las relaciones de poder (si éstas son equitativas o inequitativas), para sí poder transformarlas (tradução da autora)
} 
Dessa forma, incorporar a análise de gênero em um projeto implica, necessariamente, examinar as relações de poder existentes em uma sociedade. E, para a sua análise, é preciso identificar as diferenças existentes entre homens e mulheres, a posição e condição que ambos ocupam no seu espaço cotidiano intrafamiliar e na comunidade, de maneira geral (ZALDAÑA, 1999).

Daí se reconhece a primeira contribuição das metodologias e métodos participativos com foco em gênero para o turismo de base comunitária: por meio da identificação dessas diferenças é possível se combater a reprodução de condições desiguais no acesso aos benefícios do desenvolvimento da atividade turística em um determinado território, principalmente, por meio da participação efetiva das mulheres na implantação de projetos turísticos locais.

Concorda-se com Zaldaña (1999, p. 14) quando afirma que obter

a real participação das mulheres no desenvolvimento significa dar-lhes a oportunidade de expressar seus pontos de vista e de tomar decisões que afetam suas vidas. Significa que suas necessidades e interesses devem ser contemplados na definição dos objetivos dos projetos e serem levados em conta quando se avalia o impacto das ações desenvolvidas pelos projetos ${ }^{4}$.

Significa, portanto, estimular a autorreflexão dos sujeitos, ou seja, a reflexão sobre sua própria realidade de vida, contribuindo, assim, para o aprofundamento da tomada de consciência sobre suas relações cotidianas. Essa autorreflexão estimula nos sujeitos um posicionamento mais crítico diante da realidade e a concepção de diversas intervenções no contexto no qual esses atores estão inseridos, a partir daí, "não mais como espectadores, mas como figurantes e autores" (FREIRE, 1994, p. 44), uma vez que os sujeitos tomam, pouco a pouco, consciência de suas possibilidades de intervenção sobre sua própria realidade.

Este é o propósito do Diagnóstico Participativo com Foco em Equidade de Gênero (DPEG), proposto por Aguilar et al. (1999) e entendido como um

processo sistemático utilizado para reconhecer uma determinada situação e o porquê de sua existência, em que a construção do conhecimento se realiza com a intervenção e opiniões diferenciadas das pessoas que estão inseridas nessa situação (...) segundo seu gênero/sexo, idade e vislumbra também as relações de poder dentro da comunidade (AGUILAR et al., 1999, p. 11).

O Diagnóstico Participativo com Foco em Equidade de Gênero possui seis etapas de trabalho: 1) contextualização da realidade local ${ }^{6}$; 2) desenho do $\mathrm{DPEG}^{7}$; 3) identificação de participantes ${ }^{8}$; 4) agrupamento de informações ${ }^{9}$; 5) análise, avaliação e devolução das informações agrupadas $^{10}$; 6) formulação de conclusões e definição da estratégia de trabalho a seguir ${ }^{11}$.

Assim, acredita-se que a partir da adoção da perspectiva de Gênero em Desenvolvimento (ZALDAÑA, 1999) e do método de Diagnóstico Participativo com Foco em Equidade de Gênero (AGUILAR et al.,

\footnotetext{
4 La participación real de las mujeres en el desarrollo significa tener la oportunidad de expresar sus puntos de vista y de tomar las decisiones que afectan sus vidas. Significa que sus necesidades y intereses deben ser contemplados en la definición de los objetivos de los proyectos y ser tomadas en cuenta cuando se evalúa el impacto de las acciones desarrolladas por los proyectos (tradução da autora).

5 Proceso sistemático que sirve para reconocer una determinada situación y el porqué de su existencia, en donde la construcción del conocimiento se hace con la intervención y opiniones diferenciadas de las personas que tienen que ver con esa situación (...) según su género/sexo, edad y visibiliza también las relaciones de poder al interno de la comunidad (tradução da autora). 6 Ubicación del contexto (tradução da autora).

7 Diseño del DPEG (tradução da autora).

8 Identificación de participantes (tradução da autora).

9 Recolección de la información (tradução da autora).

10 Análisis, evaluación y devolución de la información recolectada (tradução da autora).

11 Formulación de conclusiones y definición de la estrategia de trabajo a seguir (tradução da autora).
} 
1999) seria possível se construir um modelo de planejamento turístico que tivesse como princípio norteador a busca pela equidade de gênero. Nesse sentido, os principais subsídios oferecidos pelas metodologias participativas com foco em gênero ao turismo de base comunitária são a construção coletiva de conhecimento; a valorização dos saberes existentes na coletividade, assim como todas as suas possíveis formas de expressão; a busca pela igualdade de oportunidades entre homens e mulheres nos projetos de desenvolvimento; e a transversalidade de gênero, que assegura tanto aos homens como às mulheres voz ativa na definição de objetivos e no planejamento dos projetos, de forma que as prioridades e necessidades de ambos sejam neles contempladas.

Afirma-se, ainda, que por meio das metodologias participativas com foco em gênero, é possível evidenciar a responsabilidade de ambos, homens e mulheres, na busca do desenvolvimento sustentável.

Dessa forma, com o objetivo de buscar a equidade de gênero nos projetos turísticos de base comunitária, incorporando-se propostas e métodos das metodologias participativas com foco em gênero, apresenta-se a seguir, a metodologia deste estudo de caso na Comunidade Quilombola Morro Santo Antônio.

\section{METODOLOGIA}

O trabalho de elaboração da proposta inicial de autogestão do turismo de base comunitária com foco em gênero pela Comunidade Quilombola Morro Santo Antônio fundamentou-se nos princípios do turismo de base comunitária (MITRAUD, 2003) aliados aos do Diagnóstico Participativo com Foco em Equidade de Gênero (DPEG) proposto por Aguilar et al. (1999) e da perspectiva de Gênero em Desenvolvimento (GED) concebida por Zaldaña (1999). Foi composto por quatro etapas, que serão descritas a seguir: 1) preparação para as intervenções na comunidade; 2) pensando sobre questões de gênero; 3) início do pensamento em torno do turismo de base comunitária com foco em gênero; e 4) elaboração da proposta inicial de autogestão do turismo de base comunitária com foco em gênero pela Comunidade Morro Santo Antônio.

\section{Preparação para as intervenções na comunidade}

Essa primeira etapa correspondeu ao conhecimento da comunidade, seus atores e sua dinâmica cotidiana pela pesquisadora e foi composta por três trabalhos de campo: um realizado no mês de março de 2012 e outros dois no mês de abril de 2012. Nos dois primeiros trabalhos de campo utilizou-se o método de observação participante a fim de se conhecer as relações sociais dos atores entre si e a organização territorial e religiosa da comunidade. A observação participante foi obtida por meio do contato direto da pesquisadora com o fenômeno observado, para recolher as ações dos atores em seu contexto natural, a partir da perspectiva e dos pontos de vista da investigadora (CHIZZOTTI, 2001).

Com o objetivo de se conhecer a realidade cultural, social, econômica, política, territorial e ambiental da localidade, foi usado, ainda, o método da entrevista não diretiva, entendida por Chizzotti (2001) como uma forma de se colher informações acerca de um determinado assunto por meio do discurso livre do entrevistado. Dessa forma, foram realizadas conversas informais com a comunidade local, nas quais os sujeitos puderam falar de forma aberta sobre seu cotidiano e aspectos socioculturais comunitários. Ambos os métodos - de observação participante e de entrevista não diretiva - contribuíram de forma positiva para o conhecimento da realidade de vida dos sujeitos que seriam envolvidos no processo participativo proposto neste estudo. 
Realizou-se, ainda, leitura e análise das atas das reuniões da Associação Quilombola Morro Santo Antônio de 1986 a 2011 e da cópia da documentação enviada por esta à Fundação Cultural Palmares na ocasião de seu reconhecimento como remanescente de quilombo. Tais dados possibilitaram a compreensão da história de formação da comunidade e, ao mesmo tempo, a análise do nível de articulação da população local em torno de seus interesses comuns.

Ao fim dos três trabalhos de campo foi realizado um encontro com as lideranças locais com o objetivo de se definir data, local, participantes e duração das reuniões propostas neste estudo de caso. Ficou acordado que elas aconteceriam na sede da associação (local central e que todos os moradores frequentam), em três sábados seguidos (dias 05, 12 e 19 de maio de 2012) e no horário de 14 h às $16 \mathrm{~h}$. O convite para as reuniões seria feito pelo presidente da associação, que entregou a 15 famílias uma carta escrita pela pesquisadora, na qual esclarecia os objetivos dessas reuniões.

\section{Pensando sobre questões de gênero}

Nesta etapa, foi realizada a primeira reunião com a comunidade com o objetivo de iniciar o pensamento e questionamento dos sujeitos acerca das desigualdades de gênero e a necessidade de busca pela equidade entre os sexos. Utilizou-se a dinâmica "Procura-se" (Anexo 1), proposta por Aguilar et al. (1999), com o objetivo de apresentar os participantes da reunião e iniciar o pensamento coletivo sobre as relações de gênero.

Em seguida, aplicaram-se as dinâmicas "O que é bom para os homens é bom para as mulheres também?” (Anexo 2) e "Quem faz o quê... e como faz?" (Anexo 3), também desenvolvidas por Aguilar et al. (1999), com o objetivo de se reconhecer a situação geral da comunidade em relação às desigualdades de gênero e identificar a divisão do trabalho existente nesta, respectivamente.

O planejamento dessa reunião é apresentado na tabela abaixo (Tabela 1):

Tabela 1 - Planejamento da primeira reunião

\begin{tabular}{|c|c|c|}
\hline \multicolumn{3}{|c|}{ Primeira reunião - 05/05/12 - Pensando sobre questões de gênero } \\
\hline Horário & Recurso/atividade & Conteúdo \\
\hline $14 \mathrm{~h}$ às $14 \mathrm{~h} 15$ & Exposição oral & $\begin{array}{l}\text { * Apresentação da pesquisadora. } \\
\text { * Agradecimento pela disponibilidade em contribuir com o } \\
\text { trabalho. } \\
\text { * Apresentação da proposta e objetivos do trabalho. }\end{array}$ \\
\hline $\begin{array}{l}14 \text { h15 às } \\
14 \text { h45 }\end{array}$ & Dinâmica “Procura-se” & $\begin{array}{l}\text { * Apresentação dos participantes. } \\
\text { * Início do pensamento sobre as relações de gênero. }\end{array}$ \\
\hline $\begin{array}{l}14 \mathrm{~h} 45 \text { às } \\
15 \mathrm{~h} 30\end{array}$ & $\begin{array}{l}\text { Dinâmica “O que é } \\
\text { bom para as mulheres } \\
\text { é bom para os homens } \\
\text { também?” }\end{array}$ & $\begin{array}{l}\text { * Reconhecimento da situação geral da comunidade, } \\
\text { especialmente no que diz respeito às relações de gênero } \\
\text { entre os moradores locais. }\end{array}$ \\
\hline $15 \mathrm{~h} 30$ às $16 \mathrm{~h}$ & $\begin{array}{l}\text { Dinâmica “Quem faz o } \\
\text { quê... e como faz?” }\end{array}$ & $\begin{array}{l}\text { * Identificação da divisão do trabalho entre homens e } \\
\text { mulheres na comunidade. }\end{array}$ \\
\hline $16 \mathrm{~h}$ & Encerramento/lanche & $\begin{array}{l}\text { * Agradecimento pela participação de todos. } \\
\text { * Convite para a próxima reunião. }\end{array}$ \\
\hline
\end{tabular}

Início do pensamento em torno do turismo de base comunitária com foco em gênero 
Ao fim da etapa de discussão e construção coletiva de ideias acerca das relações de gênero, na segunda reunião iniciou-se uma discussão sobre as possibilidades de a atividade turística fazer parte da dinâmica econômica, cultural e social da comunidade. Para tanto, foram realizadas as dinâmicas "Painéis coletivos" (Anexo 4) e "Papel amassado" (Anexo 5), propostas por Araújo (2011). Por meio delas foi possível (re) conhecer a identidade cultural local; problematizar o turismo em relação à realidade da comunidade; e, por fim, apresentar conceitos e características do turismo de base comunitária aos participantes. $\mathrm{O}$ planejamento dessa reunião pode ser observado a seguir (Tabela 2):

Tabela 2 - Planejamento da segunda reunião

\begin{tabular}{|c|c|c|}
\hline \multicolumn{3}{|c|}{$\begin{array}{c}\text { Segunda reunião - } 12 / 05 / 12 \text { - Início do pensamento em torno do turismo de base } \\
\text { comunitária com foco em gênero }\end{array}$} \\
\hline Horário & Recurso/atividade & Conteúdo \\
\hline $14 \mathrm{~h}$ às $14 \mathrm{~h} 15$ & Exposição oral & $\begin{array}{l}\text { * Retomada dos conceitos abordados na reunião anterior. } \\
\text { *Apresentação dos objetivos da reunião. }\end{array}$ \\
\hline $14 \mathrm{~h} 15$ às $15 \mathrm{~h}$ & $\begin{array}{l}\text { Dinâmica "Painéis } \\
\text { coletivos" }\end{array}$ & $\begin{array}{l}\text { * (Re)conhecimento do território e da identidade local. } \\
\text { * Caracterização da comunidade. } \\
\text { * Visualização dos desejos comuns da população em relação } \\
\text { à comunidade. }\end{array}$ \\
\hline $15 \mathrm{~h}$ às $15 \mathrm{~h} 15$ & $\begin{array}{l}\text { Dinâmica "Papel } \\
\text { amassado" }\end{array}$ & $\begin{array}{l}\text { * Reflexão sobre as mudanças e transformações que podem } \\
\text { ocorrer nas localidades devido à implantação do turismo. }\end{array}$ \\
\hline $\begin{array}{l}15 \mathrm{~h} 15 \text { às } \\
15 \mathrm{~h} 30\end{array}$ & Exposição oral e visual & $\begin{array}{l}\text { * Refletir sobre a possibilidade de se trabalhar o turismo de } \\
\text { base comunitária no Morro Santo Antônio. }\end{array}$ \\
\hline $\begin{array}{l}15 \text { h30 às } \\
16 \text { h15 }\end{array}$ & Exposição oral e visual & $\begin{array}{l}\text { * Pensar e registrar as ações necessárias, dificuldades } \\
\text { e condições dos atores locais para que o turismo seja } \\
\text { implantado na comunidade. }\end{array}$ \\
\hline 16h15 & Encerramento/lanche & $\begin{array}{l}\text { * Agradecimento pela participação de todos. } \\
\text { * Convite para a próxima reunião. }\end{array}$ \\
\hline
\end{tabular}

Elaboração da proposta inicial de autogestão do turismo de base comunitária com foco em gênero pela Comunidade Morro Santo Antônio

Este último encontro realizado com a comunidade se configurou como a consolidação e organização de todas as informações coletadas nas reuniões anteriores em um documento: a proposta inicial de autogestão do turismo de base comunitária pela Comunidade Morro Santo Antônio. As atividades executadas nessa reunião encontram-se detalhadas a seguir (Tabela 3):

Tabela 3 - Planejamento da terceira reunião

\begin{tabular}{l|l|l}
\hline \multicolumn{2}{c}{ Terceira reunião - 19/05/12 - Elaboração da proposta inicial de autogestão do turismo de base } \\
comunitária com foco em gênero pela comunidade
\end{tabular}




\begin{tabular}{c|c|l}
\hline \multicolumn{3}{c}{ Terceira reunião - 19/05/12 - Elaboração da proposta inicial de autogestão do turismo de base } \\
comunitária com foco em gênero pela comunidade
\end{tabular}

Para tanto, em um primeiro momento, foram retomados e validados pelos participantes os resultados das dinâmicas realizadas nas duas primeiras reuniões. Em seguida, iniciou-se a elaboração da referida proposta de autogestão do turismo de base comunitária, utilizando-se como referência o modelo de autogestão e a estrutura de planos de desenvolvimento local propostos por Buarque (2002), cuja base é a estruturação e distribuição de responsabilidades pela execução de diversas tarefas e atividades entre os atores locais.

Segundo o autor (BUARQUE, 2002), o plano de desenvolvimento gerado em um processo de planejamento participativo pode ter várias formas de apresentação. No entanto, há informações básicas que devem ser coletadas para que o plano represente, ao mesmo tempo, um referencial para a sociedade local e um cartão de visitas da localidade na sua relação com os diversos parceiros que contribuirão na realização das ações propostas nesse plano.

Buscou-se, então, responder às seguintes perguntas concretas: o que somos? (realidade atual da comunidade); de onde viemos? (sua história e evolução recente); aonde queremos chegar com o plano? (visão de futuro); o que se deve e pode fazer para chegar aonde queremos?; com que meios se podem implementar as ações?; e como se organizar para executar e acompanhar as ações? (BUARQUE, 2002). Os resultados de todo esse processo participativo serão apresentados a seguir.

\section{O INÍCIO DO PLANEJAMENTO TURÍSTICO DE BASE COMUNITÁRIA COM FOCO EM GÊNERO}

Os primeiros trabalhos de campo ${ }^{12}$ realizados no Morro Santo Antônio tiveram como objetivo principal o conhecimento da comunidade, seus atores e sua dinâmica cotidiana. Assim, a partir dessa primeira etapa foi possível observar que a associação comunitária possui um importante papel na articulação dos atores locais em torno de seus interesses comuns. Temas como a necessidade de melhorias infraestruturais em seu território, rezas e missas na igreja e opções de lazer e entretenimento dos moradores (festas e bailes, por exemplo) faziam parte da pauta de suas reuniões desde 1986, quando foi criada.

Além disso, nas entrevistas não diretivas, diversas pessoas confirmaram a existência de esforço coletivo para a melhoria e manutenção da infraestrutura local por meio de mutirões que, segundo elas, eram realizados com frequência. Diante de tais características, considerou-se a comunidade como um território propício para a construção de uma proposta de turismo de base comunitária com foco em gênero, uma

12 Primeira etapa de intervenção, de preparação para as intervenções na comunidade. 
vez que historicamente os atores locais vinham se mobilizando em torno de seus interesses comuns.

Por meio dos primeiros trabalhos de campo foi possível notar, ainda, a existência de uma realidade comum a diversos lugarejos rurais brasileiros: há poucas oportunidades de trabalho nessa comunidade quilombola, tanto para adultos como para jovens, o que faz com que haja evasão de moradores para outras localidades, como para a capital do estado, Belo Horizonte-MG, e para a sede de Itabira-MG. Segundo relatos, há mais de 40 anos a maioria dos homens do Morro busca emprego nos centros urbanos, onde ficam durante os dias úteis e retornam para casa apenas nos finais de semana. Algumas mulheres permanecem na comunidade, cuidando dos filhos; outras trabalham no município de Itabira-MG como domésticas. De acordo com o relato de algumas moradoras locais, as oportunidades de ocupação remunerada para as mulheres na comunidade são capinar e trabalhar na roça (que, segundo elas, são tarefas típicas dos homens).

Dessa forma, entendeu-se que a possibilidade de construção de uma proposta de turismo de base comunitária com foco em gênero no Morro Santo Antônio poderia se configurar como uma alternativa de emprego dentro da própria comunidade e, ao mesmo tempo, contribuir de forma positiva para a valorização do trabalho feminino.

Assim, na primeira reunião realizada com a comunidade ${ }^{13}$, buscou-se, além de conhecer as relações de gênero nela existentes, iniciar o pensamento e questionamento dos sujeitos acerca das desigualdades de gênero e a necessidade de busca pela equidade entre os sexos. Na dinâmica "Procura-se", primeira atividade realizada com os participantes, notou-se que, entre eles, os limites entre as tarefas típicas dos homens e das mulheres não eram claros, uma vez que a maioria das atividades dos homens (capinar, "pegar no pesado", buscar lenha, entre outras) também era realizada pelas mulheres da comunidade, o que gerou dúvidas quanto ao preenchimento das informações requeridas.

No entanto, quando foi solicitado que se lembrassem das atividades que somente as mulheres faziam (e os homens, não), rapidamente se lembraram das tarefas de cozinhar, fazer doces, limpar a casa, lavar vasilhas, etc., o que leva a crer que há sobrecarga de trabalho entre as mulheres que, além dos afazeres domésticos, também se dedicam a outras atividades que não são típicas do seu gênero.

Tais desigualdades de gênero foram identificadas, ainda, por meio da segunda dinâmica, "O que é bom para as mulheres é bom para os homens também?" Homens e mulheres participantes da reunião concordaram totalmente com as seguintes afirmações: a mulher pode se sentir realizada mesmo sem ter filhos; as mulheres são mais resistentes a doenças que os homens; o trabalho doméstico deveria ter um reconhecimento econômico; existem tarefas que são mais apropriadas para homens e outras que são mais adequadas às mulheres; e os homens são mais capazes e têm maior reconhecimento que as mulheres em momentos de negociação.

Discordaram totalmente das seguintes ideias: o casamento pode funcionar normalmente se o homem permanecer em casa e a mulher trabalhar fora; os homens são melhores que as mulheres para realizar atividades técnicas; as mulheres são mais confiáveis que os homens para cuidar dos recursos financeiros da comunidade; os homens representam adequadamente os interesses de toda a comunidade; os homens ocupam a maioria dos cargos de direção porque têm mais experiência em assuntos públicos; as mulheres não resistem adequadamente às pressões da vida pública; e as mulheres não sabem lidar com o poder.

13 Segunda etapa de intervenção, “Pensando sobre questões de gênero", que contou com a presença de 11 pessoas (3 homens e 8 mulheres) de diversas idades. 
Houve divergências nas opiniões dadas pelas mulheres mais velhas e as mais jovens: estas consideraram várias afirmações sexistas e aquelas, não; dados os costumes e modo de vida comum em sua época de juventude e maturidade. No entanto, de maneira geral, os presentes concordaram que é necessário haver igualdade de responsabilidades e oportunidades entre homens e mulheres na sociedade atual.

Ainda segundo os moradores locais (homens e mulheres concordaram neste aspecto), o trabalho doméstico deveria ter um reconhecimento econômico e, sobretudo, cultural, ou seja, ser valorizado como um trabalho, propriamente, pelos demais integrantes da família e, além disso, ser remunerado (uma das participantes sugeriu que seria justo o pagamento de um valor financeiro mensal pelo marido em consideração às tarefas realizadas pela esposa em casa). Precisaria ser entendido, então, como um trabalho tão penoso e digno de mérito quanto aquele que é realizado pelos homens fora de casa.

Na terceira e última dinâmica da primeira reunião - "Quem faz o quê... e como faz?" - foi possível confirmar a hipótese de que a divisão do trabalho entre os gêneros não é equitativa na comunidade, uma vez que cabe às mulheres a maior parte das tarefas cotidianas. Os participantes registraram as seguintes atividades como sendo típicas das mulheres no Morro Santo Antônio: cuidar das crianças; cuidar da criação (dos animais domésticos); lavar roupa; ler jornal; ir à igreja; estudar; ir ao salão de beleza; e cozinhar.

De acordo com a realidade local, as atividades realizadas apenas pelos homens são: sair com os amigos; dirigir; jogar futebol; fazer churrasco; e beber cerveja. As atividades comuns aos dois gêneros são: cuidar dos negócios; controlar gastos financeiros; cuidar da horta; praticar esportes; assistir TV; "pegar no pesado"; e fazer compras.

Observou-se que, apesar de haver cumplicidade entre homens e mulheres em diversas tarefas (especialmente naquelas relacionadas aos rendimentos e gastos financeiros), a vida pública é uma particularidade do sexo masculino enquanto as atividades domésticas fazem parte do universo tipicamente feminino.

Dessa forma, evidenciou-se a necessidade de construção de uma proposta de autogestão do turismo de base comunitária com foco em gênero que promovesse a valorização do trabalho doméstico da mulher ao mesmo tempo em que contribuísse para a divisão de tarefas e responsabilidades de forma justa e equitativa entre os gêneros. Tratar-se-ia, desse modo, não só da inclusão das mulheres na atividade turística, mas, também, dos homens nos diversos afazeres relativos à sua implantação e desenvolvimento.

Nesse sentido, e tendo em vista a confirmação da possibilidade de a atividade turística se tornar uma realidade no Morro Santo Antônio, a segunda reunião ${ }^{14}$ se iniciou com a dinâmica "Painéis coletivos", na qual foi proposta a caracterização do passado, presente e futuro desejado pela comunidade.

Segundo os participantes, o modo de vida atual dos moradores locais difere sobremaneira do existente no passado. Não havia eletricidade nas casas e eram poucas as pessoas que tinham condições financeiras para comprar roupas e que tiveram a oportunidade de estudar em Itabira. Às mulheres somente era permitida a realização de atividades domésticas, enquanto os homens trabalhavam fora do Morro.

$\mathrm{Na}$ representação do presente da comunidade, os moradores locais destacaram seus tradicionais eventos (Festa de Santo Antônio, Semana da Consciência Negra, Baile de Sábado Aleluia, entre outros), as aulas de capoeira para os jovens e as reuniões da associação comunitária que, segundo eles, têm número

14 Terceira etapa de intervenção, “Início do pensamento em torno do turismo de base comunitária com foco em gênero", que contou com a presença de 12 pessoas ( 2 homens e 10 mulheres) de diversas idades. 
menor de participantes, se comparado ao do passado. Destacaram, ainda, a falta de espaços de lazer para as mulheres no Morro Santo Antônio e diversas melhorias infraestruturais do presente: ônibus coletivo, energia elétrica e posto de saúde, por exemplo.

A partir da descrição do passado e presente da localidade, perguntou-se aos participantes qual seria a sua identidade cultural, uma vez que esta é um dos principais elementos de atratividade em propostas de turismo de base comunitária. Todos concordaram que as principais características do Morro Santo Antônio são a alegria e a hospitalidade dos moradores locais.

Em relação ao futuro, os participantes da reunião esperavam obter diversas conquistas tanto para a comunidade como para os moradores, especificamente. $\mathrm{O}$ acesso à internet em casa, a presença de médicos mais vezes por mês e a criação de mais opções de lazer e entretenimento para mulheres e jovens, por exemplo, foram algumas das conquistas mencionadas pelo grupo. Almejavam, ainda, alcançar maior participação das pessoas nas reuniões mensais da associação, realizar melhoria paisagística da comunidade por meio da pintura e reestruturação das casas dos moradores locais e construir chalés para serem alugados aos visitantes do Morro sem, no entanto, perder as características de área rural existentes no presente. Por fim, afirmaram que um dos principais desejos da comunidade era que as pessoas pudessem ter oportunidades de trabalho e renda em seu próprio território, diminuindo, dessa forma, a evasão de jovens e adultos para outras cidades.

Assim, diante dessa visão de futuro da comunidade, perguntou-se aos participantes se a atividade turística poderia fazer parte desta e, prontamente, eles responderam que essa era a sua expectativa. Confirmou-se, dessa maneira, a esperança da comunidade no desenvolvimento do turismo como uma forma de sanar diversos problemas locais, especialmente aqueles relacionados à escassez de oportunidades de emprego.

Realizou-se, então, a segunda dinâmica da reunião - "Papel amassado" - com o objetivo de desmistificar essa visão essencialmente positiva que a comunidade tinha em relação à atividade turística. Por meio dos papéis sulfite e cartão amassados pelos participantes, refletiu-se sobre as mudanças boas e ruins que o turismo poderia causar em uma localidade e, sobretudo, a necessidade de articulação e união da comunidade para a potencialização de seus impactos positivos e a minimização dos negativos.

Seguiu-se a essa reflexão a apresentação, pela mediadora, dos princípios e características do turismo de base comunitária com o objetivo de validar esse modelo de desenvolvimento turístico como adequado, ou não, para o Morro Santo Antônio. Ao final da exposição oral e visual, os participantes concordaram com a elaboração de uma proposta turística dentro dos moldes do turismo de base comunitária para a sua localidade, uma vez que seria construída por ela própria e para o seu benefício.

Solicitou-se, então, que os moradores locais se dividissem em três grupos e registrassem em tarjetas suas condições, possíveis dificuldades e ações necessárias para o desenvolvimento do turismo no Morro (Tabela 4). 
Tabela 4 - Condições, dificuldades e ações necessárias ao desenvolvimento do turismo de base comunitária no Morro Santo Antônio

\begin{tabular}{|c|c|c|}
\hline Condições & Dificuldades & Ações necessárias \\
\hline $\begin{array}{l}\text { * A comunidade deverá estar } \\
\text { preparada para receber bem os } \\
\text { turistas } \\
\text { * Não será aceita poluição } \\
\text { sonora } \\
\text { * Será necessário elaborar uma } \\
\text { programação de dias, horários } \\
\text { e o que há na comunidade para } \\
\text { apresentar aos turistas } \\
\text { * Ter cuidado com o tipo } \\
\text { de turista, principalmente } \\
\text { em relação às crianças e } \\
\text { adolescentes } \\
\text { * Não poluir as matas, córregos e } \\
\text { cachoeiras } \\
\text { * Os turistas deverão recolher } \\
\text { o lixo produzido por eles na } \\
\text { comunidade } \\
\text { * Não será permitido trafegar em } \\
\text { alta velocidade na localidade } \\
\text { *Criar condições para } \\
\text { transportar os turistas }\end{array}$ & $\begin{array}{l}\text { * Limpeza da cachoeira } \\
\text { * Reunião de trabalhadores } \\
\text { para a realização de atividades } \\
\text { diversas } \\
\text { * Conseguir a união de todos nas } \\
\text { ações propostas } \\
\text { * Ter a ajuda de todos os } \\
\text { moradores }\end{array}$ & $\begin{array}{l}\text { * Voltar a ter escola na } \\
\text { comunidade } \\
\text { * Fazer uma trilha na mata para } \\
\text { ser visitada pelos turistas } \\
\text { * Realizar a limpeza da sede da } \\
\text { associação } \\
\text { * Escola de artesanato } \\
\text { * Ônibus várias vezes ao dia para } \\
\text { a comunidade } \\
\text { * Realizar bailes mais vezes ao } \\
\text { ano } \\
\text { * Arrumar a pracinha com } \\
\text { bancos, brinquedos, etc. } \\
\text { * Criar áreas de lazer, cuidar do } \\
\text { campo de futebol } \\
\text { * Arrumar a estrada } \\
\text { * Missa todos os domingos } \\
\text { * Médico mais vezes por semana }\end{array}$ \\
\hline
\end{tabular}

Esses aspectos apontados pelos participantes serviram de subsídio para a construção da proposta de autogestão do turismo de base comunitária com foco em gênero na terceira reunião ${ }^{15}$ que se iniciou com a apresentação, pela mediadora, de todas as informações registradas pelos presentes nas duas reuniões anteriores e a validação dessas informações pela plenária. Os cartazes com tais informações ficaram afixados na parede, em local visível a todos, para que pudessem ser consultados na medida em que fosse necessário.

Prepararam-se outros cartazes com as perguntas-chaves, propostas por Buarque (2002) para a elaboração de planos de desenvolvimento local, que deveriam ser respondidas pela comunidade a fim de se construir a proposta inicial de autogestão do turismo de base comunitária com foco em gênero.

Assim, apresenta-se, no tópico a seguir, a proposta inicial de autogestão do turismo de base comunitária com foco em gênero pela Comunidade Morro Santo Antônio.

\section{A proposta inicial de autogestão do turismo de base comunitária com foco em gênero pela Comunidade Quilombola Morro Santo Antônio}

O que somos?

Somos moradores da Comunidade Quilombola Morro Santo Antônio, localizada na zona rural do

15 Quarta e última etapa de intervenção, "Elaboração da proposta inicial de autogestão do turismo de base comunitária com foco em gênero pela Comunidade Morro Santo Antônio", que contou com a presença de 11 pessoas ( 2 homens e 9 mulheres) de diversas idades. 
município de Itabira-MG, cuja principal característica é a hospitalidade, ou seja, gostamos de receber bem nossos visitantes. Não temos muitas opções de lazer para as mulheres na comunidade, mas possuímos eventos anuais tradicionais, como a Festa de Santo Antônio, a Semana da Consciência Negra, o Baile de Sábado Aleluia, entre outros, e as aulas de capoeira para os jovens.

Temos uma associação comunitária que, desde 1986, representa e defende nossos interesses comuns e por meio da qual elaboramos essa proposta inicial de autogestão comunitária do turismo.

\section{De onde viemos?}

Nossa comunidade surgiu na época da escravidão, há pelo menos 135 anos, quando escravos fugidos ou alforriados e negros que trabalhavam na Fazenda do Girau vieram para cá. No passado eram poucos os recursos e infraestrutura presentes no Morro Santo Antônio: não havia energia elétrica, as estradas eram ruins e eram raras as possibilidades de trabalho em nossa localidade. As mulheres ficavam cuidando da casa, enquanto os homens trabalhavam fora e visitavam suas famílias nos finais de semana ou uma vez por mês.

As possibilidades de trabalho continuam escassas dentro da comunidade, o que faz com que vários jovens se mudem para outras localidades e haja cada vez menos pessoas morando aqui. No entanto, atualmente temos posto de saúde, ônibus coletivo diário, energia elétrica, missas mensais e espaço próprio da associação comunitária, onde são realizadas reuniões e diversos eventos.

Aonde queremos chegar com essa proposta de autogestão?

Por meio desta proposta de autogestão do turismo de base comunitária com foco em gênero buscaremos melhorar a infraestrutura da comunidade para o bem-estar de todos e para nos preparar para receber turistas. Acreditamos que através da implantação e desenvolvimento do turismo no Morro será possível criar novas oportunidades de trabalho e geração de renda e permitir que as pessoas permaneçam na comunidade. Ao mesmo tempo, esperamos que o trabalho desempenhado pelas mulheres seja valorizado financeira e socialmente e que sejam criados novos espaços de lazer para elas.

O que se deve e pode fazer para chegar aonde queremos? Com que meios se podem implementar as ações?

Para atingirmos nossos objetivos registrados nesta proposta de autogestão, será necessário adotar ações tanto que criem infraestrutura turística na comunidade quanto que melhorem a infraestrutura urbana já existente no Morro Santo Antônio, conforme pode ser verificado na Tabela 5, a seguir. 
Tabela 5 - Ações para a autogestão do turismo de base comunitária

\begin{tabular}{l} 
Ações necessárias \\
\hline \\
Elaborar um roteiro ecoturístico \\
que englobe a visita à cachoeira \\
e à Mata Santo Antônio.
\end{tabular}

Construir um museu sobre a história da comunidade.
Comercializar artesanato, quitandas e doces produzidos na comunidade.

Como realizá-las?

As pessoas da comunidade já conhecem as trilhas dentro da mata. Será preciso apenas limpá-las e definir como será feito o guiamento em seu interior.

Para a limpeza da trilha será feita a convocação de toda a comunidade para a realização de um mutirão.

Pediremos auxílio de um turismólogo da prefeitura para treinar os jovens da comunidade para trabalharem como condutores turísticos.

No local onde se encontrava a casa do Padre Zé Lopão (hoje em ruínas) será construída uma casa em estilo colonial para abrigar o museu. Buscaremos apoio técnico e financeiro da prefeitura e patrocínio de empresas locais para tanto.

Será feita uma campanha para a arrecadação de utensílios, fotos e documentos antigos dos moradores locais para o acervo do museu.

A sede da associação comunitária abrigará a loja de artesanato temporariamente, enquanto o museu não ficar pronto. Buscaremos apoio financeiro de patrocinadores para a sua estruturação e aquisição de mobiliário. Uma comissão especial da associação ficará responsável por mobilizar os artesãos, quitandeiras e doceiras para que possam comercializar seus produtos em um só lugar. Assim que esse espaço estiver estruturado, os próprios artesãos farão rodízio para atendimento nos finais de semana.
Quais os recursos necessários?

Os recursos necessários serão, basicamente, humanos: Turismólogo (ajuda técnica) e pessoas da comunidade (ajuda na limpeza e manutenção das trilhas).

As ferramentas necessárias para a limpeza da trilha serão fornecidas pelos próprios moradores do Morro.

Será necessária a aquisição de mobiliário e materiais de construção; e a ajuda de museólogos, turismólogos e historiadores na concepção e implantação do museu.
Mobiliário. 


\section{Ações necessárias}

Como realizá-las?

Além da loja de artesanato, a sede da associação abrigará um restaurante onde será servido almoço e jantar.

Um grupo de mulheres será

Implantar um restaurante, onde será servida comida caseira e típica da comunidade.

responsável pela estruturação do restaurante e por preparar e servir a comida. Mobiliário e demais equipamentos (talheres, panelas, pratos, etc.) serão fornecidos por esse grupo de mulheres.

Acreditamos que a implantação do Projeto Cama e Café reforçará a identidade cultural da comunidade: a receptividade. Os moradores interessados poderão

Implantar o Projeto Cama e Café, de hospedagens domiciliares.

Implantar escola na região.

Limpar e requalificar a sede da associação comunitária. hospedar turistas em suas casas

e receberão o auxílio técnico de

um turismólogo. Essa assessoria será solicitada à prefeitura e os investimentos para a melhoria e adequação das residências serão individuais.

Uma comissão especial da associação ficará responsável por procurar vereadores, prefeito e representantes do governo estadual para reivindicar a implantação de uma escola para atender às crianças da região.

Será feita uma campanha na comunidade para que todos se empenhem na busca de patrocínios (prefeitura e empresários locais) e doações para a compra de materiais para a requalificação da sede da associação. Também serão realizadas festas para a arrecadação de recursos. Será marcado, no dia da reunião da associação, um mutirão para a realização da ação. Ferramentas e produtos de limpeza serão trazidos de casa pelos moradores da comunidade.

\section{Quais os recursos necessários?}

Mobiliário e equipamentos relativos à alimentação.
Além do investimento financeiro de cada morador que se propuser a hospedar turistas em suas residências, será necessária assessoria técnica de um turismólogo da prefeitura.

Materiais de construção, mobiliário, material didático, contratação de professores e de transporte escolar.
Materiais de construção, de limpeza e ferramentas. 


\section{Ações necessárias}

Capacitar os artesãos da comunidade através de cursos diversos.
Como realizá-las?

Apresentaremos essa necessidade na reunião da associação e pediremos 0 empenho de todos no contato com artesãos itabiranos. A ideia é fazer uma parceria com a associação de artesãos ou com eles, individualmente, para que possam ministrar cursos gratuitos na comunidade. Os materiais e matérias-primas necessárias serão compradas pelos alunos e parte delas com recursos da associação.

Reivindicar a presença de transporte coletivo mais vezes por dia na comunidade.

Construir uma praça na comunidade.

Limpar a cachoeira.
Uma comissão especial da associação irá procurar a Viação Cisne e o Departamento de Trânsito (Transita) para reivindicar esse direito.

Uma comissão especial da associação buscará patrocínio com empresas locais (Vale) e prefeitura. Assim que conseguirmos os materiais necessários, será realizado um mutirão para a construção da praça.

Uma comissão especial ficará responsável por procurar a empresa de coleta de lixo da cidade (Itaurb) para pedir mais fiscalização (para que as pessoas não joguem lixo no córrego), a instalação de lixeiras e intensificação da coleta de lixo na comunidade (quinzenal). Faremos placas educativas para sensibilizar moradores locais e visitantes.

Pediremos auxílio técnico da Secretaria de Meio Ambiente para a implantação de fossas de bananeira (bacias de evapotranspiração) para que 0 esgoto produzido não seja mais jogado no córrego.
Artesãos para ministrarem os cursos, materiais específicos e matérias-primas.

Ofícios em nome da comunidade e participação em reuniões.

Materiais de construção e equipamentos diversos. Recursos humanos: moradores da comunidade.

Lixeiras, placas educativas, materiais para a construção das fossas de bananeira. 


\begin{tabular}{|c|c|c|}
\hline Ações necessárias & Como realizá-las? & Quais os recursos necessários? \\
\hline $\begin{array}{l}\text { Construir quadra poliesportiva } \\
\text { na sede da associação. }\end{array}$ & $\begin{array}{l}\text { Onde hoje há um campo de } \\
\text { futebol na sede da associação, } \\
\text { será construída uma quadra } \\
\text { poliesportiva (para lazer } \\
\text { e realização de eventos). } \\
\text { Uma comissão especial da } \\
\text { associação buscará patrocínio } \\
\text { com empresas locais (Vale) } \\
\text { e prefeitura. Assim que } \\
\text { conseguirmos os materiais } \\
\text { necessários, será realizado um } \\
\text { mutirão para a construção da } \\
\text { quadra. }\end{array}$ & $\begin{array}{l}\text { Materiais de construção e } \\
\text { equipamentos diversos. } \\
\text { Recursos humanos: moradores } \\
\text { da comunidade. }\end{array}$ \\
\hline $\begin{array}{l}\text { Asfaltar a estrada de acesso à } \\
\text { comunidade. }\end{array}$ & $\begin{array}{l}\text { Uma comissão especial da } \\
\text { associação ficará responsável } \\
\text { por entrar em contato com a } \\
\text { empresa Vale e a prefeitura para } \\
\text { que realizem essa ação. }\end{array}$ & $\begin{array}{l}\text { Ofícios em nome da comunidade } \\
\text { e participação em reuniões. }\end{array}$ \\
\hline $\begin{array}{l}\text { Reivindicar a presença de } \\
\text { médicos mais vezes por semana } \\
\text { no posto de saúde. }\end{array}$ & $\begin{array}{l}\text { Uma comissão especial da } \\
\text { associação irá procurar a } \\
\text { Secretaria Municipal de Saúde e } \\
\text { o Conselho Municipal de Saúde } \\
\text { para reivindicar esse direito. }\end{array}$ & $\begin{array}{l}\text { Ofícios em nome da comunidade } \\
\text { e participação em reuniões. }\end{array}$ \\
\hline
\end{tabular}

Como se organizar para executar e acompanhar as ações?

Dentro da estrutura da Associação Comunitária serão criadas duas comissões compostas por, no mínimo, quatro pessoas (homens e mulheres): uma delas se dedicará à infraestrutura comunitária e a outra, à infraestrutura turística. Ambas serão responsáveis por representar a comunidade em momentos e reuniões específicas (sobretudo com representantes de empresas locais, prefeitura e conselhos municipais), articular as ações, incentivar e organizar a participação de todos os moradores nessas reuniões, campanhas e mutirões. A cada reunião da associação comunitária, os relatores dessas duas comissões irão informar a todos o andamento de cada uma das ações propostas.

Será dada prioridade às ações de infraestrutura comunitária, uma vez que são mais urgentes e darão sustentação ao início do desenvolvimento do turismo no Morro Santo Antônio. Em longo prazo, quando forem implantadas as ações de infraestrutura turística, parte dos recursos financeiros oriundos dessa atividade serão utilizados para o bem comum de toda a comunidade. Será marcada uma assembleia especial da associação para que seja definido um percentual simbólico dos lucros obtidos na venda do artesanato, quitandas e doces, guiamento nas trilhas, hospedagem e restaurante que deverá ser repassado à associação. Esse dinheiro será utilizado na manutenção dos espaços públicos, aquisição de materiais, construção do museu, folders de divulgação, compra de material de consumo para o posto de saúde, etc. 


\section{CONSIDERAÇÕES FINAIS}

Buscou-se, por meio deste estudo de caso, construir uma proposta inicial de autogestão do turismo de base comunitária com foco em gênero na Comunidade Quilombola Morro Santo Antônio. Para tanto, utilizaram-semetodologias participativas com foco em gênero como forma de se reduzirem as desigualdades de gênero comumente provocadas pelo desenvolvimento da atividade turística nos territórios.

Acredita-se que a principal contribuição dessas metodologias participativas com foco em gênero para o início do planejamento turístico de base comunitária proposto neste estudo foi possibilitar a identificação das diferenças existentes entre homens e mulheres da comunidade, a posição e condição que ambos ocupavam no seu espaço cotidiano intrafamiliar e coletivo. E, assim, conhecendo-se essas diferenças existentes na comunidade, foi possível conceber ações que as minimizassem, buscando-se evidenciar a responsabilidade de todos na busca do desenvolvimento turístico sustentável.

A necessidade de valorização do trabalho predominantemente doméstico realizado pelas mulheres, por exemplo, foi incorporada à proposta inicial de autogestão do turismo na comunidade por meio da concepção de um espaço para a comercialização de quitandas, artesanato e doces nela produzidos, além do restaurante, que seria gerido pelas moradoras do Morro. Acredita-se que, por meio dessas ações, além de se contribuir de forma positiva para a autonomia financeira feminina, seriam criadas possibilidades de trabalho dentro da comunidade e novos espaços de sociabilização para as mulheres no âmbito desta (percebeu-se, ao longo das intervenções, que a vida pública era uma particularidade dos homens).

Afirma-se, portanto, que o uso das metodologias participativas com foco em gênero aliado à proposta do turismo de base comunitária contribuiu de forma positiva para que a proposta de autogestão elaborada pela comunidade, além de ser mais crítica e contextualizada à sua realidade local, não reafirmasse as desigualdades de gênero nela existentes.

No entanto, esclarece-se que a elaboração desta proposta de autogestão do turismo de base comunitária com foco em gênero no Morro Santo Antônio configurou-se como a primeira etapa do que seria um longo processo de planejamento e gestão da atividade turística em seu território, caso a comunidade, de fato, decidisse implantar o turismo de base comunitária. Entretanto, os moradores do Morro Santo Antônio, por falta de iniciativa e mobilização em torno desse objetivo, especificamente, não concretizaram o plano elaborado por eles durante as intervenções da pesquisadora.

A comunidade continua recebendo, eventualmente, turistas interessados em conhecer o território quilombola, mas ainda não há, por parte dos moradores, nenhuma organização para atendê-los. Da mesma forma, os eventos promovidos pela Associação Quilombola Morro Santo Antônio têm grande repercussão entre os alóctones que visitam a localidade.

Nesse sentido, entende-se que seria necessário o acompanhamento técnico e profissional da implantação de cada uma das ações propostas pelos moradores durante a intervenção da pesquisadora para que se assegurasse o desenvolvimento do turismo local e, além disso, a igualdade de responsabilidades e de oportunidades entre homens e mulheres nessa atividade. Ressalta-se que as relações de gênero na comunidade também não mudaram: observam-se, ainda, as mesmas desigualdades entre homens e mulheres identificadas tanto na etapa de preparação para as intervenções da pesquisadora como na das reuniões realizadas no Morro Santo Antônio. 
Por fim, espera-se que este estudo tenha contribuído de forma positiva para se pensar a necessidade constante da busca pela equidade de gênero nos projetos turísticos atuais e que motive a elaboração de novos trabalhos no campo do turismo e relações de gênero.

\section{REFERÊNCIAS}

AGUILAR, L.; VALENCIANO, G. B.-I.; CHACON, E. Quién busca... encuentra: elaborando diagnósticos participativos con enfoque de género. Costa Rica: Master Litho, 1999, v. 2, 84 p.

ARAÚJO, M. O início do pensamento em torno do turismo de base comunitária: estudo de caso na comunidade de Galileia, município de Caparaó, Minas Gerais, Brasil. Revista Turismo em Análise, v. 22, n. 2, p. 238-275, Agosto-2011.

BESSA, A. S. M. A construção das paisagens turísticas nos descaminhos da Estrada Real. São Paulo: FAUUSP, 2011. Tese. 280p.

BRASIL. Fundação Cultural Palmares. Portaria n. 98, de 26 de novembro de 2007.

BUARQUE, S. C. Construindo o desenvolvimento local sustentável. Rio de Janeiro: Garamond, 2002, 18 op.

CHIZZOTII, A. Pesquisa em ciências humanas e sociais. São Paulo: Cortez, 2001, 164p.

DI CIOMMO, R. C. Pescadoras e pescadores: a questão da equidade de gênero em uma reserva extrativista marinha. Revista Ambiente e Sociedade, Campinas, v. X, n. 1, p. 151-163, Jan-Jun-2007.

FERNANDES, L. Turismo comunitário: uma proposta em construção - 0 caso do Brasil. In: NEUHAUS, E.; SILVA, J. S. da (Org.). Um outro turismo é possível! Reflexões sobre desigualdades, resistências e alternativas no desenvolvimento turístico. Fortaleza-CE, 2006, p. 53-57. Disponível em: 〈http://www. sits2008.org.br/oktiva.net/1893/secao/16333〉. Acesso em: 03 out. 2011.

FREIRE, P. Educação como prática da liberdade. Rio de Janeiro: Paz e Terra, 1994. 150p.

MENDONÇA, T. C. de. Turismo e participação comunitária: Prainha do Canto Verde, a "canoa" que não quebrou e a "fonte" que não secou? Rio de Janeiro: UFRJ, 2004. Dissertação. 192f.

MITRAUD, S. Manual de Ecoturismo de Base Comunitária: ferramentas para um planejamento sustentável. Brasília: WWF-Brasil, 2003, 470p.

PARISIUS, C. Treinamento de sensibilização e capacitação para as relações de gênero. In: Introdução a metodologias participativas. KLAUSMEYER, A.; RAMALHO, L. (Org.). Recife: SACTES-DED, 1995, p. 175-206.

PORTELLA, A. P. 0 turismo sexual em Pernambuco. In: NEUHAUS, E.; SILVA, J. S. da (Org.). Um outro turismo é possível! Reflexões sobre desigualdades, resistências e alternativas no desenvolvimento turístico. Fortaleza: Instituto Terramar, 2005, p. 7-12.

SILVA, J. M. Geografias feministas, sexualidades e corporalidades: desafios às práticas investigativas da ciência geográfica. In: Geografias subversivas: discursos sobre espaço, gênero e sexualidades. SILVA, J. M. (Org.). Ponta Grossa, PR: Todapalavra, 2009, p. 92-113. 
VERDEJO, M. E. Diagnóstico Rural Participativo - guia prático. Brasília, Secretaria da Agricultura Familiar, Ministério do Desenvolvimento Agrário, 2006, 137p.

ZALDAÑA, C. P. La Unión hace el poder: processos de participación y empoderamiento. Costa Rica: Master Litho, 1999, v. 5, 99p. 


\section{ANEXOS}

\section{Anexo 1 - Descrição da dinâmica "Procura-se" (AGUILAR et al., 1999, p. 25)16}

Objetivo: realizar a apresentação dos participantes e iniciar o pensamento em torno das relações de gênero.

Materiais: papéis impressos com informações a serem preenchidas pelos participantes; lápis; borrachas.

Procedimento: todos os participantes recebem uma folha na qual está escrito "Procura-se". Em um quadrado localizado na parte superior do papel deve-se fazer um desenho de si mesmo.

Em seguida, responde-se às seguintes questões:

- escreva algo que você goste de fazer e que é típico do seu gênero;

- algo que você não goste de fazer e que é típico do seu gênero;

- algo que você goste de fazer e que não é típico do seu gênero;

- algo que você não goste de fazer e que não é típico do seu gênero.

Por fim, anota-se uma recompensa que deverá ser dada à pessoa que descobrir quem escreveu essas informações. Assim que terminam de preencher a folha, estas são recolhidas e segue-se a leitura das informações, com o objetivo de encontrar as pessoas que são procuradas. Quem adivinhar ganha a recompensa prometida.

16 Denominação original: “Se busca” (AGUILAR et al., 1999). 


\section{Anexo 2 - Descrição da dinâmica " 0 que é bom para as mulheres é bom para os homens também?” (AGUILAR et al., 1999, p. 40) 17}

Objetivo: reconhecer a situação geral da comunidade em relação às desigualdades de gênero.

Materiais: cartazes; pincéis.

Procedimento: preparar cartazes com um questionário com afirmações sobre as relações entre homens e mulheres e afixá-los em um local visível para todos. Ler cada uma dessas afirmações e perguntar, separadamente, para os homens e mulheres presentes se concordam totalmente, concordam parcialmente, discordam totalmente ou discordam parcialmente com elas e registrar nos cartazes aquilo que a maioria dos homens e das mulheres apontar. Permitir que sejam feitas justificativas e contestações das opiniões uns dos outros. Identificar momentos em que mulheres e homens pensam da mesma forma e quando há divergência.

Afirmações:

1. As crianças precisam mais da ajuda da mãe do que do pai.

2. As mulheres são melhores para criarem seus filhos, por causa do seu instinto maternal.

3. Os homens são mais racionais que as mulheres e as mulheres são mais sentimentais que os homens.

4. A responsabilidade de sustentar a família é do homem.

5. Um homem não pode dar cuidado adequado às crianças.

6. A maior responsabilidade em evitar gravidez é da mulher.

7. O casamento pode funcionar normalmente se o homem permanecer em casa e a mulher trabalhar fora.

8. A mulher pode se sentir realizada mesmo sem ter filhos.

9. O homem deve ser o chefe da casa.

10. As mulheres são mais resistentes a doenças que os homens.

11. O trabalho doméstico deveria ter um reconhecimento econômico.

12. Existem tarefas que são mais apropriadas para homens e outras que são mais adequadas às mulheres.

13. Na hora de tomar decisões, os homens são melhores que as mulheres.

14. As mulheres são mais pacíficas que os homens.

15. Os homens são melhores que as mulheres para realizar atividades técnicas.

16. As mulheres são melhores que os homens para realizar atividades manuais.

17. As mulheres faltam mais ao trabalho devido a doenças e mal-estar próprios delas.

18. As mulheres são mais confiáveis que os homens para cuidar dos recursos financeiros da comunidade.

17 Denominação original: “Lo que es bueno para el ganso... es bueno para la gansa?” (AGUILAR et al., 1999). 
19. Os homens são mais capazes e tem maior reconhecimento que as mulheres em momentos de negociação.

20. Os homens são melhores que as mulheres desempenhando funções que impliquem responsabilidade e tomada de decisões.

21. As mulheres são mais eficientes que os homens em tarefas comunitárias.

22. As mulheres são mais honestas que os homens.

23. Os homens devem representar a família na hora de tomar decisões sobre o lar.

24. As mulheres que têm filhos pequenos não devem participar de atividades comunitárias, fora de casa.

25. As mulheres não devem realizar trabalhos que impliquem esforço físico.

26. Os homens representam adequadamente os interesses de toda a comunidade.

27. Os homens ocupam a maioria dos cargos de direção porque têm mais experiência em assuntos públicos.

28. As mulheres não resistem adequadamente às pressões da vida pública.

29. As mulheres não sabem lidar com o poder.

30. A mulher cuida mais da natureza que o homem.

Modelo de tabela a ser preenchida:

\begin{tabular}{l|l|l|l|l}
\hline & $\begin{array}{l}\text { Concordam } \\
\text { totalmente }\end{array}$ & $\begin{array}{l}\text { Discordam } \\
\text { totalmente }\end{array}$ & $\begin{array}{c}\text { Concordam } \\
\text { parcialmente }\end{array}$ & $\begin{array}{c}\text { Discordam } \\
\text { parcialmente }\end{array}$ \\
\hline Afirmação 1 & & & & \\
\hline Afirmação $2 \ldots$ & & & & \\
\hline
\end{tabular}




\section{Anexo 3 - Descrição da dinâmica "Quem faz o quê... e como faz?" (AGUILAR et} al., 1999, p. 48)

Objetivo: identificar a divisão do trabalho entre homens e mulheres na comunidade.

Materiais: recortes de revistas mostrando diferentes atividades cotidianas; fita-crepe; figura de homem, mulher e ambos.

Procedimento: mostrar diversas imagens que ilustram diferentes atividades cotidianas aos participantes, que deverão dizer a quem cabe aquela tarefa na comunidade ou na sua casa (homem ou mulher). Considerar a opinião da maioria e, em caso de divergência, conversar sobre a atividade representada pela figura. 


\section{Anexo 4 - Descrição da dinâmica "Painéis coletivos" (ARAÚJ0, 2011, p. 259)}

Objetivo: (re)conhecer o território e a identidade cultural local. Realizar a caracterização da comunidade a partir do ponto de vista dos atores locais.

Materiais: cartolinas; cola; tesouras; lápis; canetas coloridas; borrachas; revistas.

Procedimento: dividir os participantes em três grupos que representarão, por meio de imagens recortadas de revistas, desenhos ou palavras, o passado, presente e futuro da comunidade. Estimular os atores locais a falarem, posteriormente, sobre as características representadas nos cartazes. 


\section{Anexo 5 - Descrição da dinâmica "Papel amassado" (ARAÚJ0, 2011, p. 259)}

Objetivo: refletir sobre as possíveis mudanças que o turismo acarreta nas localidades. Reforçar a importância da articulação da comunidade para a minimização dos impactos negativos em um território.

Materiais: papel sulfite; papel-cartão.

Procedimento: cada participante recebe uma folha de papel sulfite e outra de papel-cartão do mesmo tamanho. Pede-se que eles amassem ambas as folhas, com apenas uma das mãos e, em seguida, que tentem desamassá-las. Comparam-se as marcas deixadas nos papéis com os impactos causados pela atividade turística nas localidades. 